\title{
Extending borders
}

The last 20 years of the last century, that sounds long ago but was actually the time that many of us already practiced in Rhinology or received their training, was I think the time of endoscopic sinus surgery. We learned all the possibilities of the endoscope, first mainly in limited inflammatory disease but later also because of the development of new technical possibilities like debriders, lens cleaners and probably most important curved drills more extensive surgery ${ }^{(1-4)}$. Since the beginning of the 21 ste century it is the time of endoscopic treatment of skull base tumours. In 2010 this Journal already produced an extensive overview in the European position paper on endoscopic management of tumours of the nose, paranasal sinuses and skull base ${ }^{(5)}$. In the mean time a number of papers on skull base surgery has been published in Rhinology $(3,6-11)$. With the rhinologist involvement in more and more complex benign and malignant sinus and skull base tumours we became part of endoscopic skull base teams. Team work, and in the OR dancing around each other in sometimes very narrow space needs new competences. Important skills to learn (if not already there) are real listening, questioning, respecting each other, helping, sharing the burden but also the glory, and accepting combined responsibility for the final result ${ }^{(12)}$. This issue of our Journal contains a unique paper where Valerie Lund and William Wei describe their extensive experience with curative endoscopic resection of malignant tumours of the sinus and skull base over an eighteen year period ${ }^{(13)}$. This series supports the impression that endoscopic resection offers equivalent results to conventional external procedures. The lower complication rate and peri-operative morbidity together with shorter hospital stay make an endoscopic approach which adheres to oncologic principles a more than acceptable alternative in appropriate cases. Recently two excellent books have been published on this same subject. The first: "Tumours of the nose, sinuses and nasopharynx" again by Valerie Lund, David Howard and William Wei is a major contribution to the field; you can find a longer review in this issue of the Journal. Another great book is Endonasal Endoscopic Surgery of Skull Base Tumors: an interdisciplinary approach Senior Editor: Wolfgang Draf Edited by: Ricardo Carrau, Ulrike Bockmuehl, Amin Kassam and Peter Vajkoczy. You will find a review in the December issue.

Sinonasal undifferentiated carcinoma is a rare and aggressive tumour. In this issue a series of 17 patients is described by López et al. ${ }^{(14)}$. All patients were treated using a multimodality approach with combinations of surgery, chemoradiation, adjuvant radiotherapy, and neoadjuvant chemo-therapy. The 3-year local control rate was $76 \%$ and the 5 -year rate of overall survival was $58 \%$. This is significantly better than the retrospective review of a USA national database from $1973-2010^{(15)}$ but comparable to other centres that use multimoda- lity approaches ${ }^{(16)}$.

Furthermore, in this issue there in an interesting paper of Alobid et al. ${ }^{(17)}$ on the use of the use of a pedicled lateral nasal wall flap for the reconstruction very large nasal septum perforations. Because of the extending borders of skull base surgery but also by other reasons like vasculitis ${ }^{(18)}$ or cocaine abuse ${ }^{(19)}$ we encounter the challenge to repair large nasal defects. Also in this issue a very interesting paper by Simmen et al. ${ }^{(20)}$ describing a new endoscopic surgical technique to improve nasal airflow, the "pyriform turbinoplasy". Although we know that there is a correlation between objective measures of improved airflow and patients satisfaction ${ }^{(21)}$ we are also aware of the fact that turbinoplasty is not always a long lasting solution to problems of obstruction. Simmen shows the efficacy of his method with objective measurements. Whether it stands over time, time will tell.

Finally not only new techniques extend but also European legislation and national laws can have severe impact on our practice and maybe seriously limits our borders. We use allergens for skin prick testing, nasal allergen provocation and of course immunotherapy ${ }^{(22-25)}$. Allergens used for diagnostic tests or therapy are defined as medicinal products (allergen products) in the European Union (EU). In consequence, allergens used for diagnostic purposes like skin prick tests (SPT) or nasal provocation tests (NPT) become allergen products and thus need registration and authorization. Since the financial expenses for initiation and maintenance of diagnostic allergen product authorizations far outreach possibly related revenues, the manufacturers may be forced to significantly limit their aller- gen portfolios. This will have a tremendous impact on the availability of diagnostic allergens for SPT and NPT in Europe and will make performing these tests more and more difficult.

In this issue Klimek et al. ${ }^{(26)}$ provides you with all the relevant de- tails. In the Netherlands we now have to provide a signed letter per patient and in some cases per allergen to acknowledge the use of this allergen for diagnostic purposes. At least two com- panies have stopped producing diagnostic extracts because of this, hampering optimal diagnostics. How far do we have to go? Time will tell. 


\section{References}

1. Nakayama T, Otori N, Asaka D, Okushi T, Haruna S. Endoscopic modified medial maxillectomy for odontogenic cysts and tumours. Rhinology. 2014; 52(4): 376-380.

2. Virk JS, Elmiyeh B, Stamatoglou C, Saleh HA Optimising outcomes in the management of spontaneous cerebrospinal fluid rhinorrhoea. Rhinology. 2013; 51(3): 268-274.

3. Liu SC, Wang HW, Kao HL, Hsiao PC, Su WF. Three-dimensional bone $\mathrm{CT}$ reconstruction anatomy of the vidian canal. Rhinology. 2013; 51(4): 306-314.

4. Janovic A, Antic S, Rakocevic Z, Djuric M. Paranasal sinus osteoma: is there any association with anatomical variations? Rhinology. 2013; 51(1): 54-60.

5. Lund VJ, Stammberger $H$, Nicolai $P$, Castelnuovo P, Beal T, Beham A, et al. European position paper on endoscopic management of tumours of the nose, paranasal sinuses and skull base. Rhinology Supplement. 2010 (22): 1-143.

6. Gotlib T, Kuzminska M, Held-Ziolkowska M, Niemczyk K. Asymmetry of the anterior skull base at the level of frontal ostium, a radioanatomical study. Rhinology. 2014; 52(4) 419-423.

7. Di Somma A, de Notaris M, Ensenat J, et al. The ventral route to intracranial aneurysm: from the origin towards modern transsphenoidal surgery. An historical review and current perspective. Rhinology. 2014; 52(3): 195-207.

8. Vital D, Krayenbuhl N, Bozinov O, Holzmann D. Access to the crista galli and the foramen caecum in nasal dermal sinus cysts - lessons learned in a single tertiary care centre. Rhinology. 2013; 51(1): 47-53.

9. Jangard M, Hansson J, Ragnarsson-Olding
B. Primary sinonasal malignant melanoma: a nationwide study of the Swedish population, 1960-2000. Rhinology. 2013; 51(1) 22-30.

10. Eweiss $A Z$, Lund VJ, Jay A, Rose G. Transitional cell tumours of the lacrimal drainage apparatus. Rhinology. 2013; 51(4) 349-354.

11. Ensenat J, de Notaris $M$, Sanchez $M$, et al Endoscopic endonasal surgery for skull base tumours: technique and preliminary results in a consecutive case series report. Rhinology. 2013; 51(1): 37-46.

12. McLaughlin N, Carrau RL, Kelly DF, Prevedello DM, Kassam AB. Teamwork in skull base surgery: An avenue for improvement in patient care. Surg Neurol Int. 2013; 4: 36

13. Lund VJ, Wei WI. Endoscopic surgery for malignant sinonasal tumours: an eighteen year experience. Rhinology. 2015; 53(3): 204-211.

14. López F, Suárez V, Vivanco B, Suárez C Llorente JL. Current management of sinonasal undifferentiated carcinoma. Rhinology. 2015; 53(3): 212-220.

15. Chambers KJ,Lehmann AE, Remenschnei$\operatorname{der} A$, et al. Incidence and survival patterns of sinonasal undifferentiated carcinoma in the United States. J Neurol Surg B Skull Base. 2015; 76(2): 94-100.

16. Yoshida E, Aouad R, Fragoso R, et al Improved clinical outcomes with multimodality therapy for sinonasal undifferentiated carcinoma of the head and neck. Am J Otolaryngol. 2013; 34(6): 658-663.

17. Alobid I, Mason E, Solares CA, et al. Pedicled lateral nasal wall flap for the reconstruction of the nasal septum perforation. A radioanatomical study. Rhinology. 2015; 53(3):
235-241.

18. Gottschlich S, Ambrosch P, Kramkowski D, Laudien M, Buchelt T, Gross WL, et al. Head and neck manifestations of Wegener's granulomatosis. Rhinology. 2006; 44(4): 227-233.

19. Trimarchi M, Bertazzoni G, Bussi M. Cocaine induced midline destructive lesions. Rhinology. 2014; 52(2): 104-111.

20. Simmen D, Sommer F, Briner HR, et al. The effect of "Pyriform Turbinoplasty" on nasal airflow using a virtual model. Rhinology. 2015; 53(3): 242-248.

21. Toyserkani NM, Frisch T, Von Buchwald C. Postoperative improvement in acoustic rhinometry measurements after septoplasty correlates with long-term satisfaction. Rhinology. 2013; 51(2): 171-175.

22. Graf $N$, Dinkel B, Rose $H$, et al. A critical appraisal of analyzing nasal provocation test results in allergen immunotherapy trials. Rhinology. 2014; 52(2): 137-141.

23. Cornelis M, Rombaux $P$, Jorissen M, Hellings PW. Nationwide survey on immunotherapy practice by ENT specialists. Rhinology. 2014; 52(1): 72-77.

24. Petalas K, Durham SR. Allergen immunotherapy for allergic rhinitis. Rhinology. 2013; 51(2): 99-110.

25. Kariyawasam HK, Rotiroti G, Robinson DS Sublingual immunotherapy in allergic rhinitis: indications, efficacy and safety. Rhinology. 2013; 51(1): 9-17

26. Klimek L, Hammerbacher AS, Hellings PW, et al. The influence of European legislation on the use of diagnostic test allergens for nasal allergen provocation in routine care of patients with allergic rhinitis. Rhinology. 2015; 53(3): 260-269.

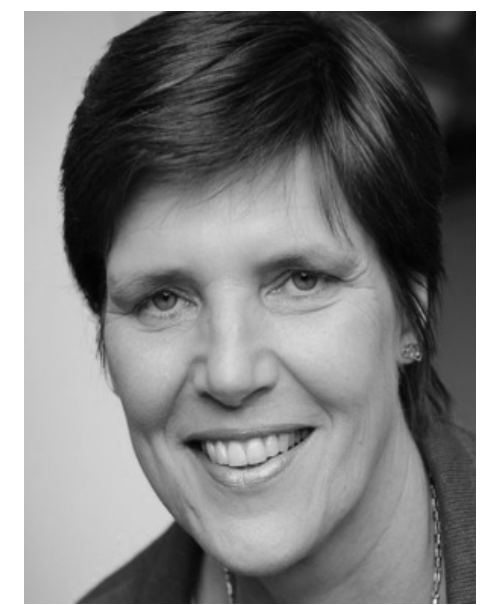

